\title{
The Triel Observatory
}

Jean-Paul Trachier

Observatoire de Triel, Groupe Astronomique des Yvelines,

F-78510 Triel, France

Although with limited equipment, this small observatory mounts a permanent exhibition and conducts various astronomical courses. It is primarily concerned with astronomical education and is visited by $5000-6000$ pupils every year.

[Text not received - Eds.]

\section{The Bruno-H.-Bürgel Observatory}

Helmut Busch

Bruno-H.-Bürgel Sternwarte, DDR-7302 Hartha (Kr. Dobeln), GDR

The observatory is both a school and public observatory. Lectures are arranged for pupils at various levels as well as courses for teachers. Since 1959 astronomy has been a compulsory subject in schools in the D.D.R. (one of only four countries in the world in which this is the case). The observatory also participates in scientific work, particularly in the field of variable stars, where it has always had very close links with Sonneberg Observatory.

[The English-language text of this contribution is published in Circular 67 of the Variable Star Section of the British Astronomical Association. - Eds.]

\section{The Strasbourg Observatory}

\section{Roger Hellot}

17 rue de la Ziegelau, F-67100 Strasbourg, France

The Alsace Group of the S.A.F. is closely associated with the Strasbourg Observatory and is responsible for supervising visits by the public after planetarium shows. The 6-inch refractor was restored by three of the amateurs and the Group has the use of the $21-\mathrm{cm}$ refractor for planetary photography and other projects. 